\title{
Weight gain and height velocity during prolonged first remission from acute lymphoblastic leukaemia
}

\author{
C P Q SAINSBURY, R G NEWCOMBE, AND I A HUGHES \\ Departments of Child Health and Medical Computing and Statistics, University of Wales College \\ of Medicine, Cardiff
}

SUMMARY A retrospective analysis of the medical records of 86 children in prolonged remission from acute lymphoblastic leukaemia was performed to calculate changes in the rate of increase in height and weight gain. The rate of increase in height decreased during initial treatment, and the potential for final adult height was not regained. Weight gain was excessive; this started during treatment and persisted into the remission years. Values of weight adjusted for height did not return to values found before treatment until eight years after diagnosis. Several factors can account for this weight gain, but there is a practical need to provide dietary advice, particularly when chemotherapy is stopped.

Advances in the management of children with acute lymphoblastic leukaemia have led to a noticeable improvement in prognosis. Remission is induced in $90-95 \%$ of children, of whom half can be expected to survive for five years; many will have been cured. ${ }^{1}$ Several studies have reported on the growth of children treated for malignant disease.$^{2-7}$ Rate of growth is decreased, most noticeably during the first year of treatment. Although the rate of growth usually returns to normal after the completion of chemotherapy, there is a small but significant reduction in the eventual height reached. None of the studies have reported data on weight gain. We describe a retrospective analysis of weight gain in children with acute lymphoblastic leukaemia in relation to rate of increase in height and the duration of remission.

\section{Patients and methods}

The children were treated for acute lymphoblastic leukaemia at three regional centres (Edinburgh, Glasgow, and Cardiff) and were aged less than 10 years at diagnosis. All had entered into first remission and none had relapsed. There was no evidence of leukaemic infiltration of the brain or any other disease that may have affected growth adversely.

The records of 86 children were examined, 49 of whom were girls. The mean age at diagnosis was $5 \cdot 1$ years (range $0 \cdot \dot{8}-9 \cdot 8$ years). Each child diagnosed after 1970 was treated according to the current national acute lymphoblastic leukaemia trial. Sixty eight children received chemotherapy for three years and 15 for two years. Three patients who started treatment before 1970 were treated for four, five, and seven years, respectively. Cranial irradiation (1800-2400 rads) and craniospinal irradiation

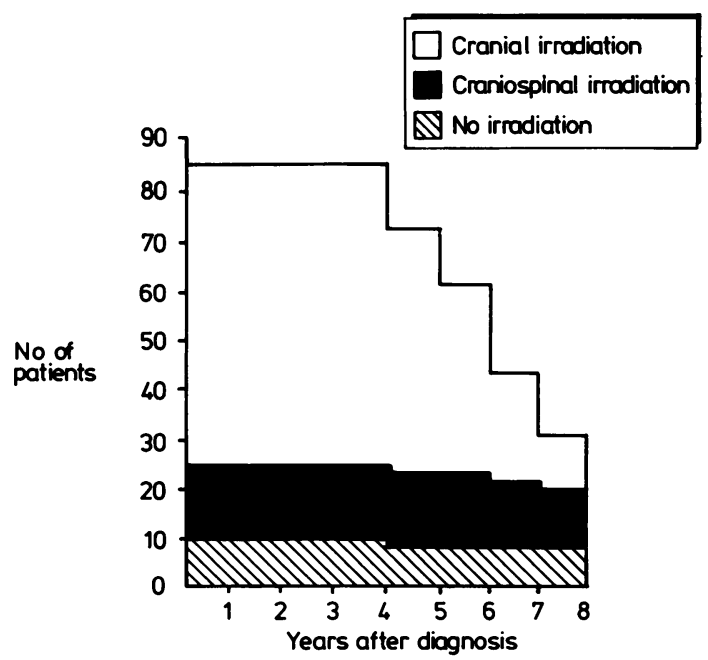

Fig. 1 Total number of children studied in relation to type of radiotherapy and number of years' observation. 
(850-1000 rads) were given to 62 and 14 children, respectively. Ten children received no radiotherapy (Fig. 1). All patients were followed up for a minimum of four years and $35 \%$ for eight years (see Fig. 1).

Measurements of height and weight performed at the time of diagnosis (before treatment) and at yearly intervals thereafter were recorded. Measurements of growth were taken before each maintenance cycle to reduce the acute effect of a course of steroids on weight gain.

Height adjusted for age, weight adjusted for age, and weight adjusted for height and age were calculated, as described by Cole, ${ }^{8}$ based on the standards of Tanner and Whitehouse. ${ }^{9}$ Results were expressed as a percentage with $100 \%$ being the mean value for age.

Data were analysed with and without logarithmic transformation to produce compatible results for the three variables. Changes in these variables with time from diagnosis were assessed on a within subject basis by paired $t$ tests and an analysis of variance model, which took into account that different subsets of children were represented in data for the different years from diagnosis. Similarly, differences between groups defined by type of radiotherapy, sex, age at diagnosis, and treatment centre were assessed simultaneously by analysis of variance. The analysis was also performed with adjustment for the corresponding value at admission as covariate to determine if changes in height and weight depended on these factors.

\section{Results}

Figure 2 shows the mean values for height for age at
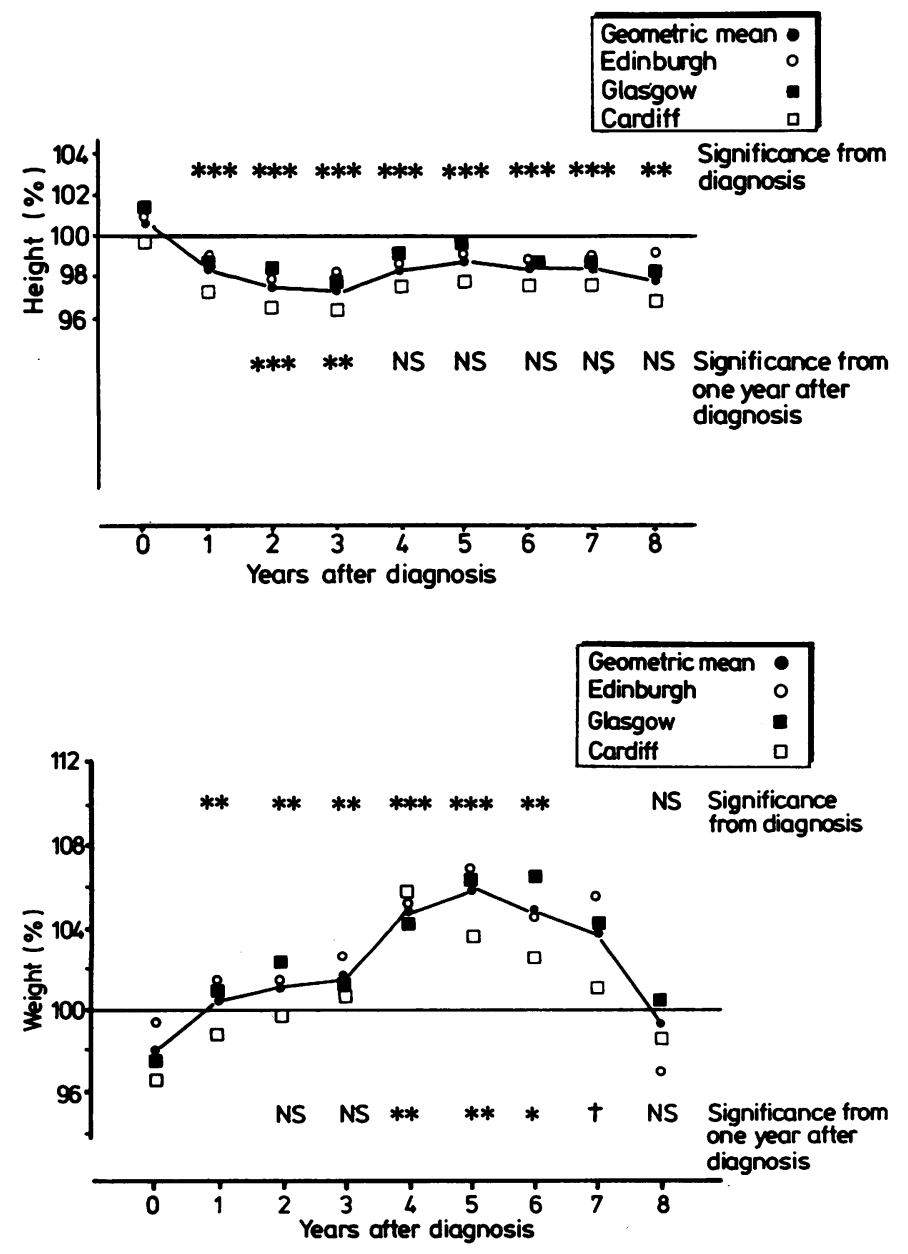

Fig. 2 Change in percentage height for age after diagnosis of acute lymphoblastic leukaemia. Significance compared with values at diagnosis and one year after diagnosis are shown.

${ }^{*} \mathrm{P}<0.001,{ }^{* *} \mathrm{P}<0.01,{ }^{* *} \mathrm{P}<0.05,+\mathrm{P}=0.05$ $0 \cdot 1, \mathrm{NS}=\mathrm{P}>0 \cdot 1$.

Fig. 3 Change in percentage weight for age after diagnosis of acute lymphoblastic leukaemia. Significance compared with values at diagnosis and one year after diagnosis are shown.

${ }^{*} \mathrm{P}<0.001,{ }^{*} \mathrm{P}<0.01,{ }^{* * *} \mathrm{P}<0.05,+\mathrm{P}=0.05$ $0 \cdot 1, \mathrm{NS}=\mathrm{P}>0 \cdot 1$. 


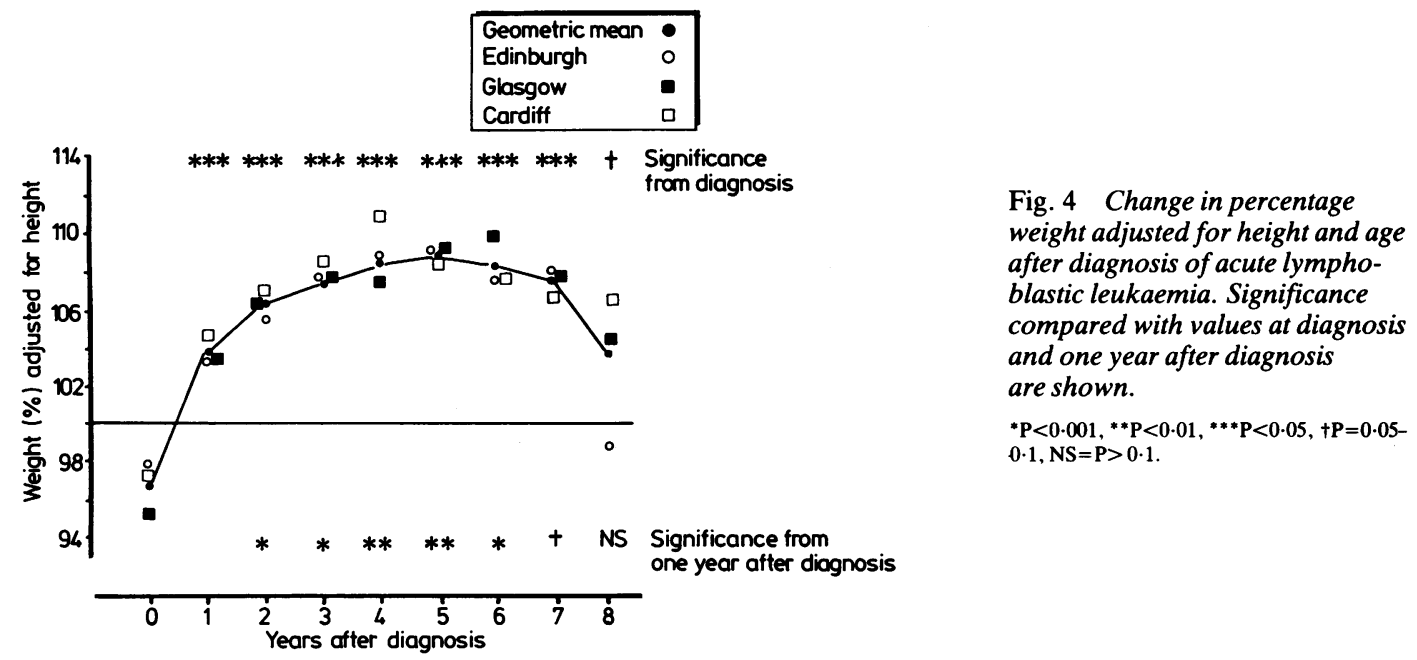

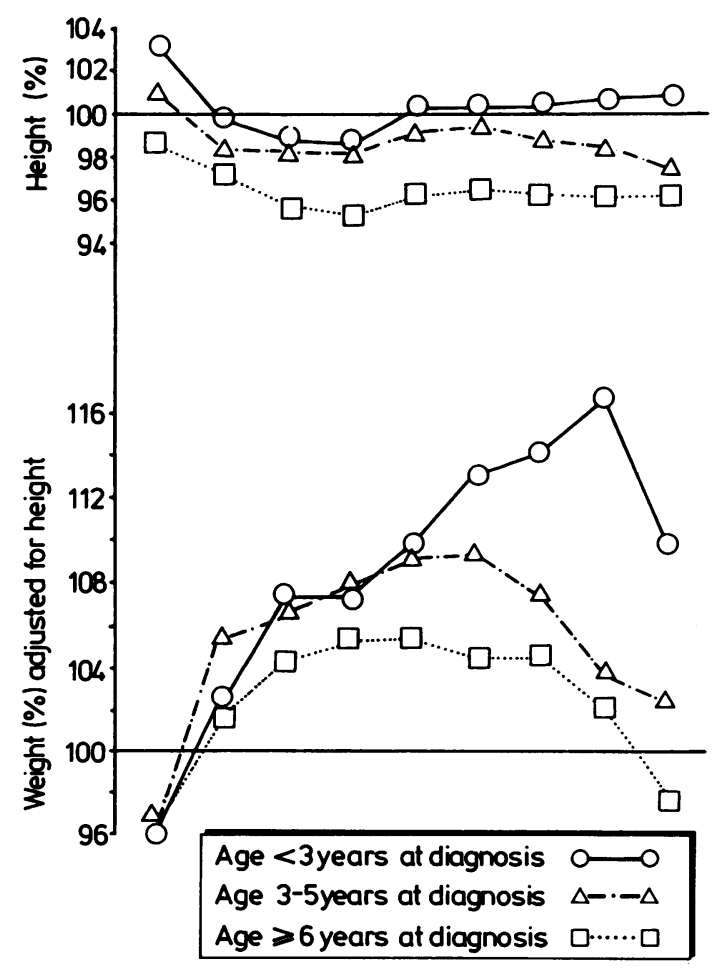

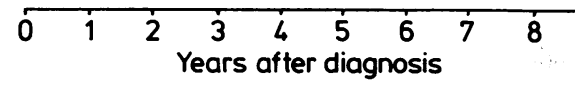

Fig. 5 Change in percentage height for age and weight adjusted for height in relation to age at diagnosis. diagnosis and at yearly intervals. The significance of these values compared with those at diagnosis and one year after diagnosis are also shown. The children were slightly taller than normal at diagnosis. During treatment there was a decrease in the rate of increase in height, but after three years there was a return towards normal. The last height attained remained significantly below values found before treatment.

The mean values for weight for age at diagnosis, during treatment, and subsequently during remission together with their significance are shown in Fig. 3. A small increase in weight occurred during the first three years followed by a noticeable increase that persisted until the seventh year after diagnosis.

Figure 4 gives values of weight adjusted for height and age. The children were relatively thin at diagnosis but gained weight rapidly during the first year. This weight gain persisted throughout treatment and into the seventh year after diagnosis before returning towards values found before treatment.

The centre of treatment, type of radiotherapy, and sex of the child made no difference to the changes in growth that were observed, as shown by analysis of covariance. The age at diagnosis, however, did have some effect on subsequent growth. Children aged less than 3 years at diagnosis were more likely to regain their potential height than older children and had a more noticeable and prolonged period of weight gain (Fig. 5).

\section{Discussion}

This retrospective study showed that children with 
acute lymphoblastic leukaemia were slightly taller at diagnosis but were underweight compared with children of the same age. Our values for height agree with a report on stature at presentation in children with acute lymphoblastic leukaemia. ${ }^{10}$ Although the cause of this is not known, the use of growth standards derived from a population of children studied about 30 years ago may partially explain the differences. ${ }^{9}$ Certainly, non-specific symptoms, including anorexia, may precede the diagnosis of acute lymphoblastic leukaemia and lead to some loss in weight without affecting the rate of increase in height.

Spinal irradiation can inhibit growth of the spine to a variable degree. ${ }^{11} 12$ Our study showed no significant difference in the height attained between children who received craniospinal irradiation and those who did not. Unfortunately, sitting height was not measured routinely. A significant effect may not have been seen due to the small numbers in this group or because the spinal irradiation dose used had a minimum effect on spinal growth. ${ }^{13}$ The changes in the rate of increase in height were the same whichever type of radiotherapy was used, suggesting that radiotherapy was not a causative factor.

Several factors may affect weight gain, including drugs, diet, radiotherapy, and physical exercise. Induction chemotherapy includes the use of high dose steroids given over a period of weeks. Children often gain weight rapidly during this time. Continued use of steroids given as recurrent short pulses throughout the maintenance cycle must also be responsible for some of the persistent weight gain. This does not, of course, explain why a further increase in weight occurs after chemotherapy is stopped. Other drugs such as methotrexate, which may cause malabsorption, ${ }^{14}$ are unlikely to promote weight gain.

Damage to the hypothalamus or pituitary by radiation may result in minor abnormalities in the secretion of growth hormones, ${ }^{245}$ probably due to a deficiency of hypothalamic growth hormone releasing factor. ${ }^{15}$ In most children with acute lymphoblastic leukaemia this does not appear to affect the rate of growth. Hypothalamic damage may cause obesity, but this has not been described after cranial irradiation. ${ }^{16}$ Hypothalamic obesity has been reported in children with acute leukaemia, but this has always been after leukaemic infiltration of the brain. $^{17}$

The psychological effects on a family when a child has acute leukaemia are complex and varied. ${ }^{18-20}$ The threat of death or serious adverse effects due to treatment causes parents to react differently to their children than they would normally. They try to allow their child to lead a life as free from unpleasantness as possible. This may result in poor dietary habits with the excessive consumption of high energy foods, such as sweets and crisps, and lead to excessive weight gain.

Lack of exercise may also contribute to the excess weight gain. Parents probably restrict physical activity, particularly while the child is receiving treatment. In this study the children had a relatively uncomplicated course of treatment and probably led normal active lives during the years after treatment.

There was a noticeable decrease in adjusted weight for height between the seventh and eighth years after diagnosis. Although the number of patients in this group was smaller (30), the change probably reflects the effect of a pubertal growth spurt.

The results of this study show that children treated successfully for acute lymphoblastic leukaemia gain excessive weight. This starts early in the treatment phase and persists for many years. Although several factors probably contribute to the weight gain, we suggest that parents be given dietary advice. The appropriate time for this would be at the end of chemotherapy.

We thank the paediatric oncologists at Edinburgh, Glasgow, and Cardiff for access to the medical records of children at these centres.

\section{References}

' Lanzkowsky P. Paediatric oncology: a treatise for the clinician. New York: McGraw-Hill Inc, 1983: 74-5.

2 Shalet SM. Abnormalities of growth and gonadal function in children treated with malignant disease: a review. $J R$ Soc Med 1981;75:641-7.

3 Griffin NK, Wadsworth J. Effect of malignant disease on growth in children. Arch Dis Child 1980;55:600-3.

4 Swift PGE, Hearney PJ, Dalton RG, Bullimore JA, Mott MG, Savage DCL. Growth and hormonal status of children treated for acute lymphoblastic leukaemia. Arch Dis Child 1978;53: 890-4.

5 Shalet SM, Price DA. Effect of treatment of malignant disease on growth in children. Arch Dis Child 1981;56:235-8.

${ }^{6}$ Shalet SM, Price DA, Beardwell CG, Morris Jones PH, Pearson $D$. Normal growth despite abnormalities of growth hormone secretion in children treated for acute leukaemia. $J$ Pediatr 1979;94:715-22.

7 Price DA, Shalet SM, Beardwell CG,Hann IM, Morris Jones PH. Serum somatomedin activity in children with acute lymphoblastic leukaemia. Pediatr Res 1978;12:159.

${ }^{8}$ Cole TJ. A method for assessing age-standardised weight-forheight in children seen cross-sectionally. Ann Hum Biol 1979;6:249-68.

9 Tanner JM, Whitehouse RH, Takaishi M. Standards from birth to maturity for height, weight, height velocity and weight velocity. British children 1965, Part II. Arch Dis Child 1966; 41:613-35.

10 Broomhall J, May R, Lilleyman JS, Milner RDG. Height and lymphoblastic leukaemia. Arch Dis Child 1983;58:300-1.

1 Probert JC, Parker BR, Kaplan HS. Growth retardation in children after megavoltage irradiation of the spine. Cancer 1973;32:634-9. 
12 Park TS, Hoffman HJ, Hendrick B, et al. Medulloblastoma: clinical presentation and management. Experience at the Hospital for Sick Children, Toronto 1950-80. J Neurosurg 1983;58:543-52.

13 Bloom HJG, Wallace ENK, Henk JM. The treatment and prognosis of medulloblastoma in children. $A J R$ 1969;105: 43-62.

${ }^{14}$ Lewis IJ, Mainwaring D, Martin J. Enteropathy complicating maintenance therapy in acute lymphoblastic leukaemia. Arch Dis Child 1982;57:663-7.

15 Ahmed SR, Shalet SM. Hypothalamic growth hormone releasing factor deficiency following cranial irradiation. Clin Endocrinol 1984;21:483-8.

16 Bray AB, Gallagher JR. Manifestations of hypothalamic obesity in man: a comprehensive investigation of eight patients and a review of the literature. Medicine 1975;54:301-30.
${ }^{17}$ Barak Y, Liban E. Hypothalamic hyperphagia, obesity and disturbed behaviour in acute leukaemia. Acta Paediatr Scand 1968;57:153-6.

18 Schuler D, Polcz A, Révész T, et al. Psychological late effects of leukaemia and their prevention. Med Pediatr Oncol 1981;9: 191-4.

19 Eiser C. Psychological development of the child with leukaemia: a review. J Behav Med 1979;2:141-57.

${ }^{20}$ Maguire GP. Psychological consequences of childhood leukaemia. J R Soc Med 1980;73:217-8.

Correspondence to Dr I A Hughes, Department of Child Health, University of Wales College of Medicine, Cardiff CF4 4XN.

Received 21 March 1985.

\section{Shredding of manuscripts}

From 1 January 1986 articles submitted for publication will not be returned if the paper is rejected unless this is requested at the time of submission. Authors whose papers are rejected will be advised of the decision; the manuscripts will be kept under security for three months to deal with any enquiries and then destroyed by shredding. 